\title{
NATURE AND UTILITY OF SOME UNSTEADY CHARACTERISTICS MIER OF A FOSSIL-FUEL-FIRED BOILER
}

\author{
A.L. BERLAD \\ January 1980
}

DEPARTMENT OF ENERGY AND ENVIRONMENT

BROOKHAVEN NATIONAL LABORATORY UPTON, NEW YORK 11973 


\section{DISCLAIMER}

This report was prepared as an account of work sponsored by an agency of the United States Government. Neither the United States Government nor any agency Thereof, nor any of their employees, makes any warranty, express or implied, or assumes any legal liability or responsibility for the accuracy, completeness, or usefulness of any information, apparatus, product, or process disclosed, or represents that its use would not infringe privately owned rights. Reference herein to any specific commercial product, process, or service by trade name, trademark, manufacturer, or otherwise does not necessarily constitute or imply its endorsement, recommendation, or favoring by the United States Government or any agency thereof. The views and opinions of authors expressed herein do not necessarily state or reflect those of the United States Government or any agency thereof. 


\section{DISCLAIMER}

Portions of this document may be illegible in electronic image products. Images are produced from the best available original document. 


\title{
NATURE AND UTILITY OF SOME UNSTEADY CHARACTERISTICS OF A FOSSIL-FUEL-FIRED BOILER
}

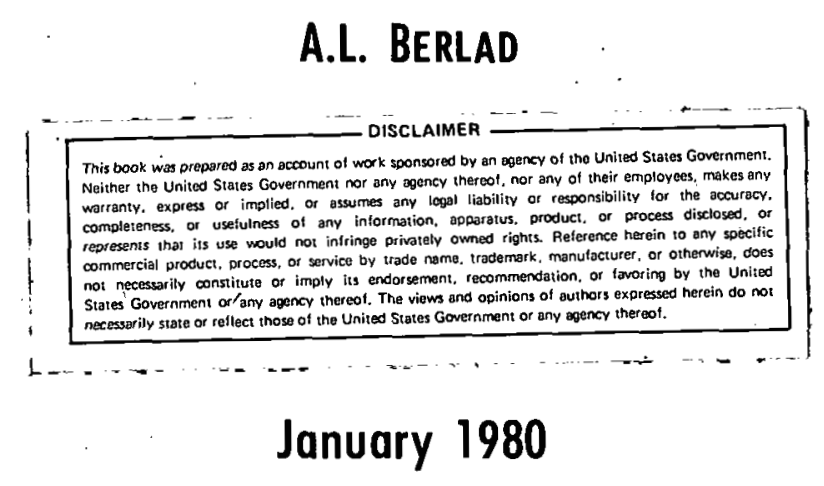

\author{
F.J. Salzano, Head \\ ENERGY STORAGE AND CONVERSION DIVISION
}

\author{
ENERGY TECHNOLOGY PROGRAMS \\ DEPARTMENT OF ENERGY AND ENVIRONMENT \\ BROOKHAVEN NATIONAL LABORATORY \\ ASSOCIATED UNIVERSITIES, INC.
}

UNDER CONTRACT NO. DE-ACO2-7OCHOOO16 WITH THE

UNITED STATES DEPARTMENT OF ENERGY 


\section{DISCLAIMER}

This bouk was prepaicd ás an account of work sponsored by an agency of the United Stiales Guviriment. Neither the United States Government nor any agency therenf, nur ally of their employces, makcs any warranty, express or implied, or assumes any legal liability or responsibility for the accuracy, completeness, or usefulness of any information, apparatus, product, or process disclosed, or represents that its use would not infringe privately owned rights. Reference herein to any specific commercial producl, prucess, ur service by trade name, trademark, manufaoturor, or othorwise, does not necessarily constitute or imply its endorsement, recommendation, or favoring by the United States Government or any agency thereof. The views and opinions of authors expressed herein do not necessarily state or reflect those of the United States Government or any agency thereof.

Printed in the United States of America Available from

National Technical Information Service

$$
\text { U.S. Department of Commerce }
$$

5285 Port Royal Road

Springfield, VA 22161

Price: Printed Copy $\$ 4.00$; Microfiche $\$ 3.00$ 


\section{ABSTRACT}

The dimensionless temperature rise rate of an initially cold fossil-fuelfired boiler and the boiler's off-cycle cooling rate are examined analytically. If the thermal relaxation times for the non-water-containing boiler elements are to be relatively short, simplified expressions are found for the time variation of the dimensionless boiler temperature. The utility of these analytic results is examined in the light of experimental observations. 


\section{INTRODUCTION}

It has been reported that the rate of rise of boiler water temperature is approximately constant in time after a brief initial transient, when a cold residential boiler is heated by a steady combustion source. The boiler in question served no external load. It is also reported that the boiler cool-down period (after achievement of a peak desired temperature) corresponds to an exponential decay of boiler water temperature with time. The purpose of this study is to examine the gross heat transfer, thermal storage, and energy release rate mechanisms which underlie these observations.

The heating of a cold boiler "to temperature" by a quasi-steady combustion process involves time-dependent heat transfer within and thermal energy storage in the nonuniform, nonisothermal boiler. In the usually accepted sense, the process is nonsteady. This despite the quasi-steady combustion process. Nevertheless, the reported observations indicate certain regularities in major portions of the time periods which describe the "heat-up" and "cool-down" processes. It is interesting to examine, then, the physical nature of these regularities and their relation, if any, to the boiler's steady state characteristics (e.g., steady state efficiency).

It is also known that a boiler's cycle efficiency is related to its "cooldown" characteristics. Accordingly, it is interesting to examine the relations, if any, between "cool-down" regularities and "cycle efficiency."

\section{BOILER "HEAT-UP" FROM COLD INITIAL CONDITIONS - SUBJECT TO NO HEATING LOAD}

A typical residential boiler consists of a spatially nonuniform distribution of material elements. Each element has its own thermophysical properties. At initial time, the system is taken to be isothermal (cold) and its total enthalpy and enthalpy distribution are deducible, once its detailed internal structure and material constituency are known. Immediately after ignition, the system is highly nonisothermal and nonsteady. Nevertheless, its instantaneous elemental and total enthalpy are well defined and deducible if the complete time-dependent temperature field is specified. In general, the complete time-dependent temperature field is not sufficiently well investigated to be "known." It is, however, useful to study the gross physical features of the boiler's heat-up period and to examine whether certain approximate truths are implied by the aforementioned ${ }^{l}$ observations. Consider the disposal of enthalpy resulting from the heat liberated by the combustion process, where the rate of combustion heat release is steady and the entire system is initially at $\left(T_{U}\right)$.

$$
\dot{\mathrm{m}}_{f} \Delta_{C}=h_{f, B}\left(T_{f}-T_{B}\right)+h_{f, j}\left(T_{f}-T_{A}\right)+h_{\text {stack }}\left(\frac{T_{f}+a \bar{T}_{B}}{2}-T_{A}\right)=\text { constant }
$$

where

$$
\begin{aligned}
& \dot{\mathrm{m}}_{\mathrm{f}} \quad=\text { steady state mass flow rate of fuel, } \\
& \Delta_{\mathrm{c}} \quad-\text { heat of combustion, } \\
& \mathrm{h}_{\mathrm{f}, \mathrm{B}} \quad \begin{array}{l}
\text { effective heat transfer coefficient between the flame gases and } \\
\text { the heat exchanger, }
\end{array}
\end{aligned}
$$




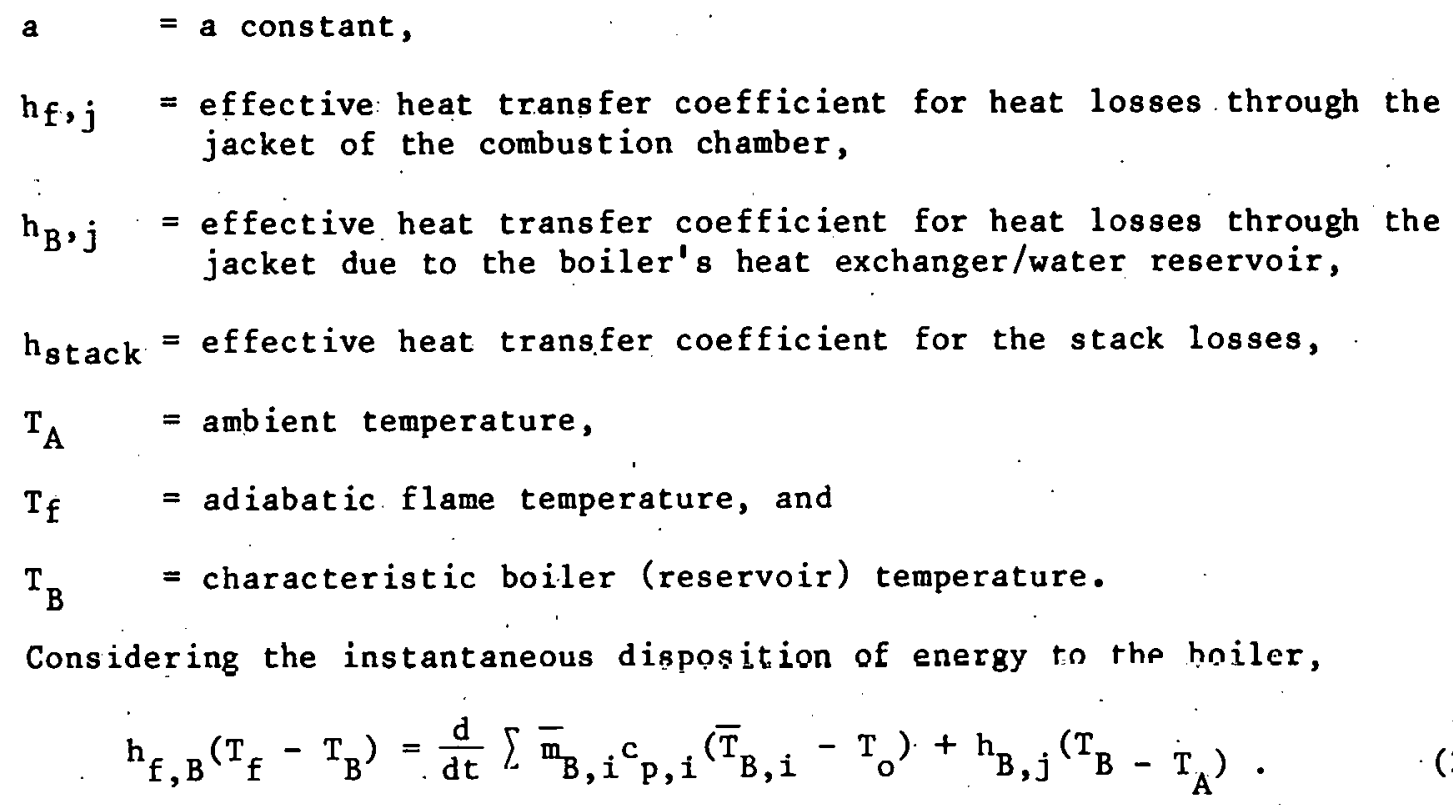

From Eqs. (1) and (2),

$$
\begin{aligned}
\dot{\mathrm{m}}_{f} \Delta_{c} & =\frac{d}{d t} \sum \bar{m}_{B, i} c_{p, i}\left(\bar{T}_{B, i}-T_{o}\right)+h_{\text {stack }} \frac{T_{f}+a \bar{T}_{B, i}}{2}-T_{A} \\
& +h_{B, j}\left(\bar{T}_{B}-T_{A}\right)+h_{f, j}\left(T_{f}-T_{A}\right) .
\end{aligned}
$$

We may define an efficiency, $\eta_{q}$, in terms of the effectiveness of the rate of enthalpy storage in the boiler, compared with the rate of energy release by the combustion process,

$$
\begin{aligned}
& \eta_{\mathrm{q}}=\frac{\frac{\mathrm{d}}{\mathrm{dt}} \sum_{\sum_{\mathrm{B}, i} \bar{c}_{\mathrm{P}, i} \overline{\mathrm{T}}_{\mathrm{B}, i}}^{\dot{\mathrm{m}}_{\mathrm{f}} \Delta_{\mathrm{c}}}}{\eta_{\mathrm{q}}}=\frac{\overline{\mathrm{m}}_{\mathrm{B}, 1} \dot{\mathrm{c}}_{\mathrm{p}, 1} \mathrm{~T}_{\mathrm{B}, 1}+\mathrm{c}_{\mathrm{p}, 1} \dot{\mathrm{T}}_{\mathrm{B}, 1}+\overline{\mathrm{m}}_{\mathrm{B}, 2} \dot{\mathrm{c}}_{\mathrm{p}, 2} \mathrm{~T}_{\mathrm{B}, 2}+\mathrm{c}_{\mathrm{P}, 2} \dot{\mathrm{T}}_{\mathrm{B}, 2}+\ldots}{\dot{\mathrm{m}}_{\mathrm{f}} \Delta_{\mathrm{C}}}
\end{aligned}
$$

In general, the numerator is time (or temperature) dependent whereas the denominator is not. In general, $n_{q}$ is not a constant.

$\underline{I f}$, after some given (initial) time period; all $\overline{\mathrm{m}}_{B}$ values but one have come (approximately) to a quasi-steady condition, then $\mathrm{B}_{\mathrm{q}} \mathrm{i}$. (5) becomes 


$$
n_{q}=\frac{\bar{m}_{B, 1}\left[\left(\dot{c}_{p, 1}\right) T_{B, 1}+\left(c_{p, 1}\right)\left(\dot{T}_{B, 1}\right)\right]}{\dot{m}_{f^{\prime}} \Delta_{c}} .
$$

If, additionally, the only nonequilibrated component is the boiler water (and its immediate envelope), then, since $c_{p, 1}$ varies by only some $2 \%$ over the temperature range of boiler operation,

$$
\eta_{\mathrm{q}}=\left(\frac{\overline{\mathrm{m}}_{\mathrm{B}, 1_{\mathrm{p}, 1} \mathrm{I}_{\mathrm{B}, I}}}{\dot{\mathrm{m}}_{\mathrm{f}} \Delta_{\mathrm{c}}}\right)
$$

It has been reported for a number of observations that.

$$
\dot{\mathrm{T}}_{\mathrm{B}, 1}=\text { constant }
$$

over a substantial period of the heating of a boiler (from ambient to "temperature"). If so, $\eta_{q}$ is also constant. The assumption that thermal equilibration of all $m_{i}$ (except $m_{1}$ ) has occurred after some time implies that

$$
\begin{aligned}
& h_{f, j}\left(T_{f}-T_{A}\right)=\text { constant, after an "initial" period, } \\
& h_{B, j}\left(T_{B}-T_{A}\right) \text { varies linearly with } T_{B} \text {, and } \\
& h_{\text {stack }}\left(\frac{T_{f}+a T_{B}}{2}\right)-T_{A} \text { varies linearly with } T_{B^{*}}
\end{aligned}
$$

Then

$$
\begin{aligned}
\dot{\mathrm{m}}_{\mathrm{f}} \Delta_{C} & =\mathrm{h}_{\mathrm{f}, \mathrm{B}}\left(\mathrm{T}_{\mathrm{f}}-\mathrm{T}_{\mathrm{B}}\right)+\cos t+\mathrm{h}_{\mathrm{B}, j}\left(\mathrm{~T}_{\mathrm{B}}-\mathrm{T}_{\mathrm{A}}\right)+\mathrm{h}_{\text {stack }}\left(\frac{\mathrm{T}_{\mathrm{f}}+a \mathrm{~T}_{\mathrm{B}}}{2}-\mathrm{T}_{\mathrm{A}}\right) \\
& =\mathrm{a} \text { linear function of temperature - but also a constant. }
\end{aligned}
$$

Consequently, from Eq. (2),

$$
h_{f, B}\left(T_{f}-T_{B}\right)=\overline{m_{B} c_{p, B} \dot{T}_{B}}
$$

and

$$
\begin{aligned}
0 & =-h_{f, B} \dot{T}_{B}+h_{B, j}\left(\dot{T}_{B}\right)+\frac{a}{2} h_{\text {stack }}\left(\dot{T}_{B}\right) \\
& =\left(h_{B, j}+\frac{a}{2} h_{\text {stack }}-h_{f, B}\right) \dot{T}_{B},
\end{aligned}
$$


or

$$
h_{f, B}=h_{B, j}+\frac{a}{2} h_{\text {stack }}
$$

$\therefore$ from Eqs. (8) and (10)

$$
\left(h_{B, j}+\frac{a}{2} h_{\text {stack }}\right)\left(T_{f}-T_{B}\right)=\overline{m_{B} c_{p, B}} \dot{T}_{B}
$$

$$
\frac{d T_{B}}{d t}=\frac{h_{B, j}+\frac{a}{2} h_{\text {stack }}}{m_{B} c_{p, B}}\left(T_{f}-T_{B}\right)
$$

and the rate of rise of boiler temperature is not a constant (it is an exponential). 'But if $\mathrm{T}_{\mathrm{f}} \gg \mathrm{T}_{\mathrm{B}}$, then $\mathrm{dT}_{\mathrm{B}} / \mathrm{dt}=\overline{\mathrm{over}}$ a small range of $\mathrm{T}_{\mathrm{B}}$ values. Equation (11) has the solution

$$
\mathrm{T}_{\mathrm{B}}=\mathrm{T}_{\mathrm{f}}-\operatorname{Aexp}[-\mu \mathrm{t}]
$$

where

$$
\mu=\left[\frac{h_{B, j}+\frac{a}{2} h_{s t a c k}}{\overline{m_{B} c_{p, B}}}\right]
$$

When values of $T_{B}$ can be experimentally measured over a range of validity of Eq. (12), then, for $t_{1} \leq t \leq t_{2}$, both $A$ and $\mu$ can be determined.

The Efficiency, $n_{q}$ :

If the assumptions leading to Eq. (6) are applicable during the period $\mathrm{t}_{1} \leq \mathrm{t} \leq \mathrm{t}_{2}$ the Eqs. ( 6 ) and (il) yield

$$
\eta_{q}=\frac{\left.\bar{m}_{D, 1}\left[\dot{c}_{\mu, 1} I_{D, 1}+c_{\mu, 1}^{i}{ }^{\mu\left(I^{\prime}\right.}-\dot{I}_{B, 1}\right)\right]}{\dot{m}_{f} \Delta c} \text {. }
$$

As noted earlier, the denominator is time invariant but the numerator, in general, is not. If, however, one assumes that $\dot{c}_{p, 1}$ is very small because

(a) the effective specific heat of the reservoir is due primarily to water, with a very small contribution by the reservoir envelope, and

(b) the effective specific heat of the reservoir is almost independent of temperature in the $\mathrm{T}_{B}$ range of interest, 
then

$$
\eta_{q} \approx \frac{\bar{m}_{B, 1} c_{p, 1} \mu\left(T_{f}-T_{B, 1}\right)}{\dot{m}_{f} \Delta_{c}}
$$

The Steady State Efficiency, $\eta_{S}$, and Steady State Boiler Operation:

Under conditions of steady state boiler operation,

$$
\dot{\mathrm{m}}_{\mathrm{f}} \Delta_{C}=h_{f, B}\left(T_{f}-T_{B}\right)+h_{f, j}\left(T_{f}-T_{A}\right)+h_{\text {stack }} \frac{T_{f}+a \bar{T}_{B}}{2}
$$

and

$$
h_{f, B}\left(T_{f}-T_{B}\right)-h_{B, j}\left(T_{B}-T_{A}\right)=n_{s} \dot{m}_{f} \Delta_{C}
$$

and

$$
\eta_{s}=\frac{h_{f, B}\left(T_{f}-T_{B}\right)-h_{B, j}\left(T_{B}-T_{A}\right)}{\dot{m}_{f} \Delta_{C}} .
$$

If the reservoir jacket. losses are small, then

$$
n_{s}=\frac{h_{f, B}\left(T_{f}-T_{B, 1}\right)}{\dot{m}_{f} \Delta_{c}}
$$

and $n_{s}$ is proportional to $n_{q}$; namely,

$$
\frac{n_{s}}{n_{q}}=\frac{h_{f, B}}{h_{B, j}+\left(\frac{a}{2}\right) h_{\text {stack }}}
$$

Note that the constant of proportionality is dependent on the specifics of the boiler and need not be the same for all boilers.

Experimental determination of the approximately steady value of $n_{\text {by }}$ bq. (15) may be used with experimental determination of $\eta_{s}$ (jacket losses neglected) by $\mathrm{Eq}$. (16) to determine

$$
\left[\frac{h_{f, B}}{\bar{m}_{B, 1}{ }^{c} p^{\mu}}\right]
$$

or

$$
\left[\frac{h_{f, B}}{h_{B, j}+\frac{a}{2} h_{\text {stack }}}\right] \text {. }
$$




\section{A Boiler's Off-Cycle Losses:}

A boiler's off-cycle losses derive from a combination of jacket losses and free convective losses. Let us define

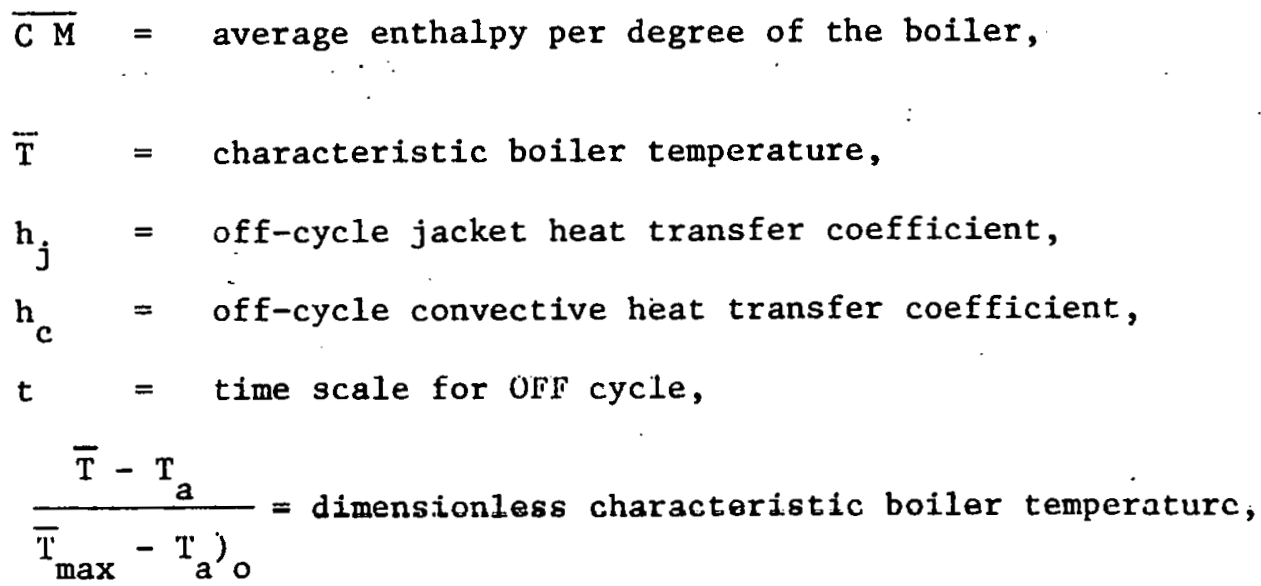

and subscripts

$$
\begin{aligned}
& \quad \quad=\text { time equals zero (beginning of OFF cycle), } \\
& c \quad=\text { free convection, and } \\
& j \quad=\text { jacket. }
\end{aligned}
$$

Then we can write a simple time-dependent energy conservation equation which describes the cooling rate of the boiler, during the OFF cycle. Note that none of the physical variables requires any knowledge of stack gas temperature:

$$
\overline{C_{p} M}\left(\frac{d \bar{T}}{d t}\right)=-h_{j}\left(\bar{T}-T_{a}\right)-h_{c}\left(\bar{T}-T_{a}\right) ;
$$

then

$$
\left(\frac{d \bar{T}}{d t}\right)=-\left[\frac{h_{1}+h_{c}}{\left(\overline{C_{p} M}\right)}\right]\left(\bar{T}-T_{a}\right)
$$

or

$$
\frac{d\left(\bar{T}-T_{a}\right)}{\left(\bar{T}-T_{a}\right)}=-\left[\frac{h_{j}+H_{c}}{\overline{C_{p} M}}\right] d t
$$

and

$$
\ln \left(\bar{T}-T_{a}\right)=-\left(\frac{h_{j}+h_{c}}{\overline{C_{p} M}}\right)\left(t-t_{o}\right),
$$




$$
\left(\bar{T}-T_{a}\right)=\operatorname{Aexp}-\frac{h_{j}+h_{c}}{\overline{C_{p} M}} t
$$

For $t=o$,

$$
\left(\bar{T}-T_{a}\right)=\left(\bar{T}_{\max }-T_{a}\right)_{0}=A ;
$$

thus,

$$
\frac{\bar{T}-T_{a}}{\left(\bar{T}_{\max }-T_{a}\right)}=\exp -\left[\left(\frac{h_{j}+h_{c}}{\overline{C_{p} M}}\right)\right] t
$$

In general, $\bar{T}$ and $\overline{C M}$ are experimentally unknown prior to the completion of the boiler's thermal equllibration, which occurs during the period $0 \leq t \leq \tau$. where $\tau_{e}=$ equilibration period).

This provides expected experimental results such as those illustrated in Figure 1.

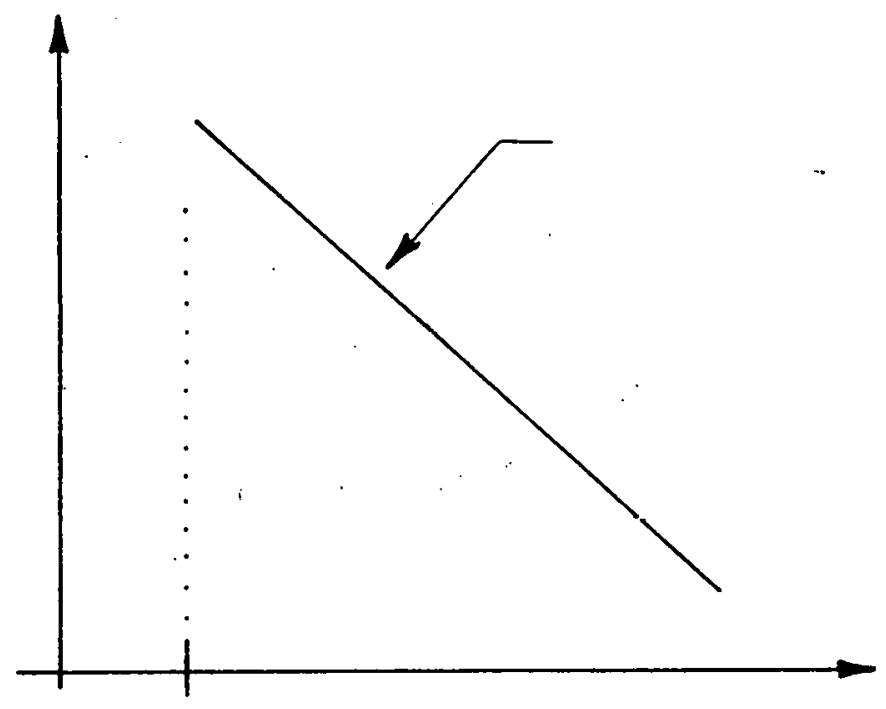

Figure 1. Cooling curve for off-cycle losses.

Eq. (24) and Figure 1 show that the the rate of off-cycle cooling is exponential in time with a decay coefficient which is determined primarily by the heat transfer coefficients for the off-cycle jacket losses and for the off-cycle free convective losses. 
Inasmuch as cooling curves of the type shown in Figure 1 are experimentally determinable for any given boiler system, quantitative measurements can be made on the off-cycle performance of various boilers as well as various boiler refit actions. Some of these are discussed below.

Consider a boiler whose cooling curve has been observed, thereby yielding $S_{i}=-\left(h_{j}+h_{c}\right) /(\overline{C M})$ for the boiler. The boiler may then be fitted (in the laboratoty) with a fast-acting, insulated ("perfect") stack vent damper and the cooling curve redetermined. This corresponds to the case where $h_{c}=0$ and the cooling curve slope is given by

$$
\mathrm{S}_{\mathrm{B}}=-\left(\mathrm{h}_{\mathrm{j}} / \overline{\mathrm{C}_{\mathrm{P}} \mathrm{M}}\right. \text {. }
$$

The "perfect" stack vent damper may then be removed and the boiler heavily insulated. Determination of the resulting cooling curve corresponds to $h_{j}=0$ and

$$
\varepsilon_{C}=-\left(h_{c} / \overline{C_{p} M}\right. \text {. }
$$

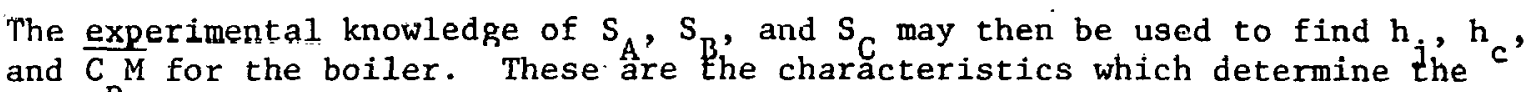
coolihg curve for the unmodified boiler.

Consider now that the effectiveness of a given stack vent damper installation is to be assessed. Install and operate the stack vent damper as desired and experimentally determine

$$
s_{v}=-\left(h_{j}+h_{c}^{*}\right)\left(\overline{C_{p}^{M}}\right.
$$

where

$$
\begin{aligned}
& h_{c}^{*}= \text { the modified heat transfer coefficient for the free convective } \\
& \text { losses for the system. }
\end{aligned}
$$

Inasmuch as $S_{D}, h_{i}$, and $\overline{C_{p} M}$ are known, the experiment then determines, $h_{\varphi}^{*}$ for the mod1,1ed system.

Thus, by a series of experiments on off-cycle cooling curves, the performance merits of various devices designed to decrease $h_{c}$ is determinable.

The Retention-Head Burner and the Suppression of Off-Cycle Losses:

It is expected that a retention-head burner, substituted for an ordinary burner, will decrease the $h$ value for the system. This effect is due to the suppression of air leaks at ${ }^{c}$ the botton of the boiler. Quantitatively, this effect is measurable by experimental study of the boiler's cooling curve during the off-cycle period. When a retention-head burner is substituted for an ordinary one and the of $f$-cycle cooling curve redetermined, $h^{* *}$ is directly deduced. One may define a figure of excellence for a convection $1 \delta$ ss inhibitor retrofit:

$$
\varepsilon_{c}^{* *} \equiv\left[\frac{h_{c}-h_{c}^{* *}}{h_{c}}\right]
$$

where $0 \leq \varepsilon_{c} \leq 1$. Here $\varepsilon_{c}=0$ corresponds to no improvement and $\varepsilon_{c}=1$ corresponds to tine maximum possible improvement. 
Similar kinds of experiments may be performed to evaluate the effectiveness of improved jacket insulation. Here, a corresponding figure of excellence for a jacket loss inhibitor retrofit is

$$
\varepsilon_{j}^{*} \equiv\left(\frac{h_{j}-h_{j}^{*}}{h_{j}}\right)
$$
where $0 \leq \varepsilon_{j}^{*} \leq 1$. Here $\varepsilon_{\dot{j}}=0$ corresponds to no improvement and $\varepsilon_{j}^{*}=1$ cor-
responds to the maximum possible improvement.

\section{Summary Remarks:}

A boiler that is heated by a steady state combustion process, but is not delivering hot water to a load, has been found to display a characteristic internal enthalpy storage rate pattern. One may define $\eta_{q}$ to be the ratio of this enthalpy storage rate to the rate of energy release by the combustion process. Under special circumstances, $\eta_{q}$ is found to be approximately constant. In general, $n_{g}$ is not equal to $n_{s}$, the classical steady state efficiency.

This study also considered the character of a boiler's standby cooling rate, when it is not serving a load and when it is not being heated by the combustion process. Equation (24) and Figure (1) provide quantitative statements of this standby cooling rate law. The boiler's dimensionless temperature is found theoretically to decay in time, according to an exponential decay law. This is in agreement with the experiment findings of reference (1). Prime determinants of the exponential decay rates are the heat transfer coefficients for the off-cycle jacket losses and for the off-cycle natural convective losses. 